\title{
Development of New Casing Treatment Configuration*
}

\author{
Vitaliy Yu. NEZYM**
}

\begin{abstract}
Circumferential grooves over a rotor blade tips are used for improving axial flow compressor performances. Such casing treatment facility extends a stable operation range in most cases, but decreases compressor efficiency as a rule. There are presented results of parametric investigation of grooves of traditional and new configurations. Development of new groove constructions must permit combining of stable operation range extension with efficiency increase. Model on basis of Group Method of Data Handling may help designing groove configurations with improved performances.
\end{abstract}

Key Words: Axial Compressor, Performances, Casing Treatment, Grooves, Statistical Model, Group Method of Data Handling

\section{Introduction}

As is well known, flow in a multistage, axial flow compressor is complex by nature because of the proximity of moving blade rows, the buildup of endwall boundary layers, the presence of leakage and secondary flows, etc.

The presence of tip clearance between rotor blades and casing is a constituent part of compressor construction, but a source of energy loss too. The significant cause of compressor performance deterioration with time is the increase of blade tip clearance. This may result from erosion, by the atmospheric grit, which is centrifuged to flow predominantly along the outer annulus wall, or by blade location problems. Location errors may result from the whirling and general flexibility of the rotor and engine structure, particularly in long compressor assemblies, or by inadequate design precautions against the different radial growth of blades and casing throughout the working envelope. Tip clearance effects are especially severe when short blades are used. At outlet end of the compressor, the boundary layer and tip clearance losses may become excessive relative to the region of effective, unblocked flow if the hub/tip diameter ratio rises above about 0.92 ; with a resultant loss of efficiency and performance.

So, the presence of tip clearance between rotating blades and compressor casing has an unfavorable influence upon compressor stage performances. Application of abradable insert in a casing over rotating blades permits

* Received 14th July, 2004 (No. 03-5082)

** SEPI ESIME Culhuacan, National Polytechnic Institute (Mexico), Av. Santa Ana No. 1000, Col. San Francisco Culhuacan, Del. Coyoacan, México D.F., C.P. 04430, México. E-mail: nezym@mail.ru reducing tip clearance to zero value practically. And such means as casing treatment is used efficiently too.

\section{Nomenclature}

$A:$ stall operation range

$b$ : blade profile chord, $\mathrm{m}$

$\left(\frac{b}{t}\right)$ : cascade solidity

$c_{p}$ : specific heat at constant pressure, $\frac{\mathrm{kJ}}{\mathrm{kg} \cdot \mathrm{K}}$

$\bar{c}$ : relative maximum thickness of blade profile

$C$ : constant

$\bar{d}:$ rotor hub/tip ratio

$D$ : rotor diameter, $\mathrm{mm}$

$\mathrm{GV}$ : guide vane

$h:$ height of blade; depth of groove, $\mathrm{mm}$

$\bar{h}$ : blade aspect ratio

$\bar{H}=\frac{c_{p} T_{1}^{*}\left(\pi_{c}^{* 0.286}-1\right)}{U_{t 1}^{2}}:$ coefficient of isentropic head

$\begin{aligned} \bar{H}_{T}= & \frac{\bar{H}}{\eta}: \text { coefficient of theoretical head } \\ & l: \text { length, } \mathrm{mm}\end{aligned}$

$m:$ air mass flow, $\frac{\mathrm{kg}}{\mathrm{s}}$

$M$ : Mach number

$n:$ number of grooves

$r$ : correlation coefficient

$\mathrm{R}$ : rotor

$R e$ : Reynolds number

$S$ : absolute tip clearance, $\mathrm{mm}$ $\bar{S}=\frac{S}{h_{1}} \times 100:$ relative tip clearance, $\%$

$t:$ distance of groove location, $\mathrm{mm}$

$T$ : temperature, $\mathrm{K}$ 
$U:$ flow circumferential velocity, $\frac{\mathrm{m}}{\mathrm{s}}$

$X$ : argument

$Y$ : function

$z:$ number of blades

$\varepsilon$ : blade curvature angle, degree; effective tip clearance, $\mathrm{mm}$

$\bar{\varepsilon}=\frac{\varepsilon}{h_{1}} \times 100:$ relative effective tip clearance, $\%$

$\phi=\frac{m}{U_{t 1}}$ : flow velocity coefficient

$\eta$ : isentropic efficiency; peak efficiency

$\pi$ : pressure ratio

$\theta$ : blade stagger angle, degree

$\Delta:$ change of parameter

3-D : three-dimensional

\section{Subscripts}

$b$ : relative to chord

$c$ : compressor; absolute velocity; crosspiece

$d:$ device

exp : experimental

$f:$ first

$g:$ groove

$m:$ mean; at mean radius

mod : model

$p:$ pressure; projection of blade chord

$R:$ rotor

red : reduced

$s:$ stall

$t:$ tip (outer)

$T:$ theoretical

$u$ : ultimate

$1:$ at the inlet (of groove; of rotor); for efficiency

2 : at the outlet (of groove; of rotor); for stable operation range

3.0 : with relative effective tip clearance equal $3.0 \%$

4,6 : only for the configurations 4 and 6

* : total (parameter)

\section{Casing Treatment Application}

An application of casing treatment for perfection of axial flow compressors may be explained by various reasons. Casing treatment was used as a traditional approach for extension of compressor stable operation range $^{(1)-(4), \text { etc. }}$. Historically casing treatment in the form of annular grooves in compressor casing (Fig. 1 (a)) is the most known one. This construction is characterized by great simplicity. Greitzer, E.M. et al. have presented ${ }^{(5)}$ the main conclusions of casing treatment (in the form of grooves and slots) use. Among these are the next:

- The use of a grooved casing can provide substantial improvement in compressor stall range over a smooth wall casing (baseline).

- The use of a grooved casing can lead to somewhat increased efficiency over a smooth wall casing, but in the most cases these configurations have some efficiency

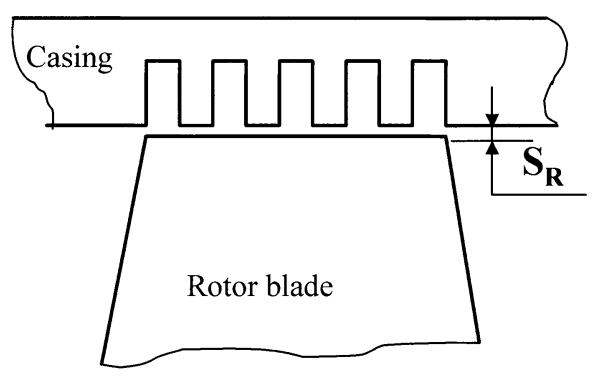

(a)
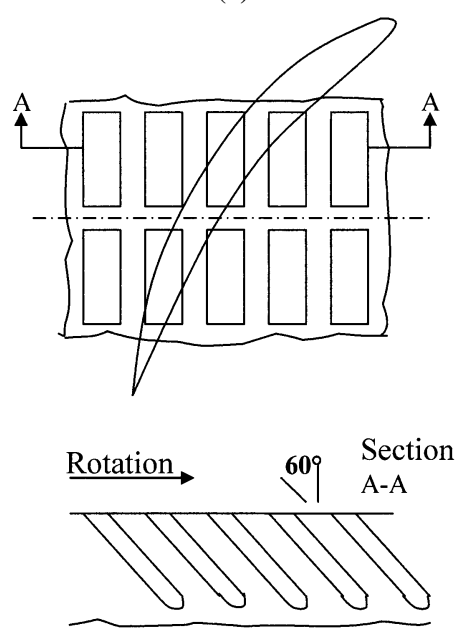

(b)

Fig. 1 Typical groove casing treatment

penalty.

- These configurations which give increased efficiency are not as effective in increasing the stall range.

It is important that in most cases stable operation range increasing is accompanied by compressor efficiency decreasing. But the positive results are possible too. For example, in the work ${ }^{(6)}$ seven grooves of $9.5 \mathrm{~mm}$ height and $1.6 \mathrm{~mm}$ width was used for compressor stage performance improving. As a result, maximum adiabatic efficiency was increased for the uniform inlet flow: by $0.95 \%$ at relative rotor speed 1.0 , by $4.76 \%$ at 0.9 and by $3.09 \%$ at 0.7 relative speeds.

However, different treatments have different effectiveness. Perhaps the most successful example of casing treatment application for reducing the stall conditions occurrence is use of the axial skewed slots (Fig. 1(b)). An essential feature of the design is inclination of the slots so that flows emerging from them would possess swirl in the sense to the rotor motion. These axial skewed grooves have been found to be extremely effective in stall margin improvement in a wide variety of compressors.

But the problem of reasoned optimization of a slot size and configuration, development new casing treatment constructions is rather empirical indeed. Experimental results pertinent to variety of annular grooves in an axial compressor casing are presented below. 


\section{Results of Groove Constructions Research}

Groove tests have been carried out with stages of tenstage subsonic axial compressor of the aviation engine AI24 (for passenger liners). The main parameters of tested objects (double-stage compressors V+VI and VIII+IX, rotor IX) are presented in Table 1. Tests were also made on the rotor R-VIII, one-and-half-stage blocks V+R-VI, VIII+R-IX and stage IX. The profiles have circle mean lines. Design flow coefficient of the stage IX (basic for the tests) $\phi=0.52$, coefficient of theoretical head $\bar{H}_{T}=0.278$, reduced tip circumferential velocity $U_{t_{\text {red }}}=211 \frac{\mathrm{m}}{\mathrm{s}}$. Testing was done at a Mach number $M_{c}=0.38$ and a Reynolds number $\operatorname{Re}_{b}=3.05 \times 10^{5}$. The stage has axial inlet flow due to special inlet guide vane, and practically axial outlet flow. Adiabatic head was measured with the help of total pressure combs upstream and downstream of the cascades, theoretical head - with the help of torque measurement at pendulous stator. The experimental procedure used multiple measurements with subsequent statistical data processing and has provided the accuracy of determination the stable operation range near $0.5 \%$ (at the confidence level 95\%). The experimental curves of the stage IX in basic variant (without grooves) are shown in Fig. 2. Every rhombic mark depicts the results of twelve measurements processing.

$\Delta \eta$ and $\Delta A$ changes were calculated as the next:

$$
\begin{aligned}
& \Delta \eta=\frac{\eta_{g}-\eta}{\eta} \times 100,(\%) \\
& \Delta A=\frac{\left[1-\left(\phi_{s} / \phi\right)\right]-\left[1-\left(\phi_{s} / \phi\right)\right]_{g}}{\left[1-\left(\phi_{s} / \phi\right)\right]} \times 100,(\%),
\end{aligned}
$$

where $\eta_{g}$ and $\eta$ - isentropic peak efficiencies (total parameters) with/without grooves, $\phi_{s}$ and $\phi-$ stall and design flow coefficients.

Typical (traditional) circumferential groove casing treatment over a rotor blade (Fig. 3) may be featured by number of grooves $n_{g}$, one radial $\left(h_{g}\right)$ and five axial $\left(l_{d}\right.$, $\left.l_{g}, l_{c}, t_{1}, t_{2}\right)$ geometric dimensions. However, it is more

Table 1 Main parameters of tested compressor objects

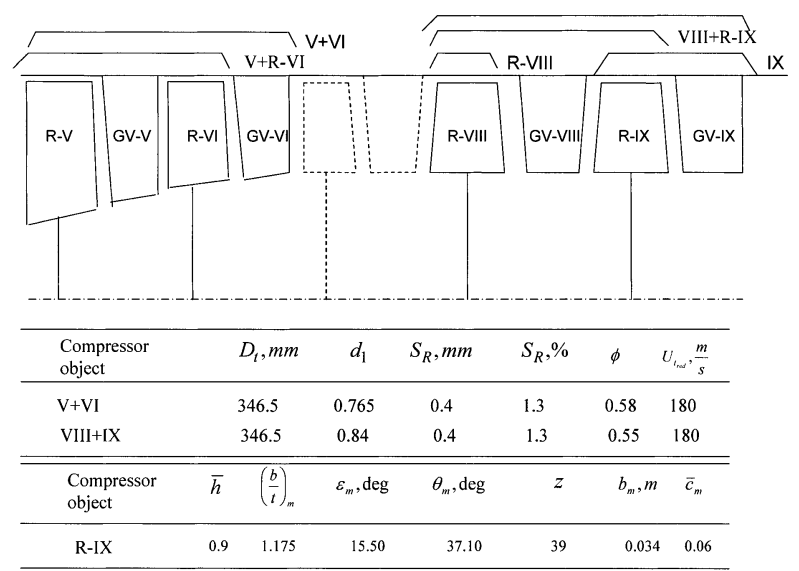

suitable to use relative geometric parameters (for example, $\left.\frac{h_{g}}{l_{g}}, \frac{l_{c}}{l_{g}}, \frac{t_{1}}{l_{p}}, \frac{t_{2}}{l_{p}}\right)$.

Note: $l_{p}$ is an axial blade chord projection.

The compressor objects were tested with the traditional and new (advanced) grooves (Figs. 4 and 5). The new configurations (2-, 3-, and 4) are featured first of all by different groove depth $h_{g}$ along blade chord projection, and irregular distribution of the depth in axial direction. So such configurations are featured in addition by a depth of the first, mean and ultimate groove $\left(h_{f}, h_{m}, h_{u}\right)$, by a distance between device elements $l_{m}$, and by an effective tip clearance $\varepsilon$. Then it is suitable to use relative geometric parameters, for example, $\frac{h_{f}}{h_{m}}, \frac{h_{u}}{h_{m}}, \frac{l_{m}}{l_{d}},\left(\frac{h_{f, u}}{h_{m}}\right)_{4,6}$.

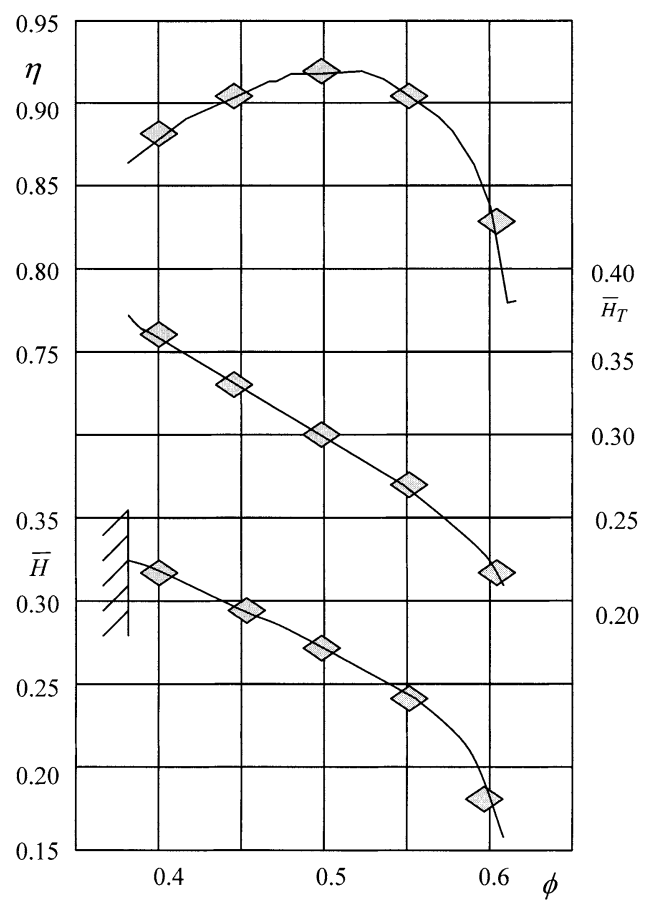

Fig. 2 Performance curves of the AI-24-IX stage with baseline

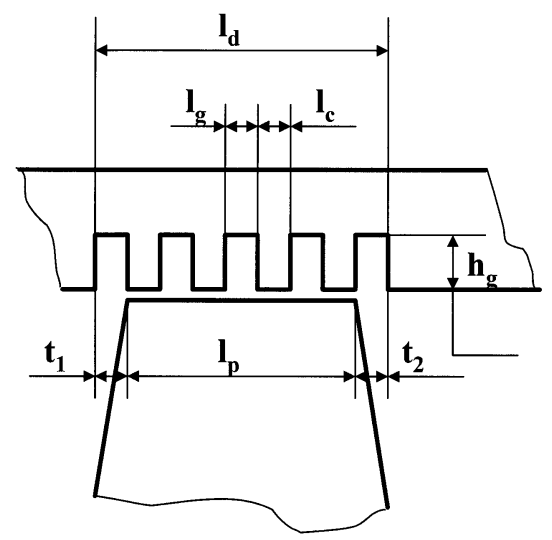

Fig. 3 Main geometric parameters of groove configuration 

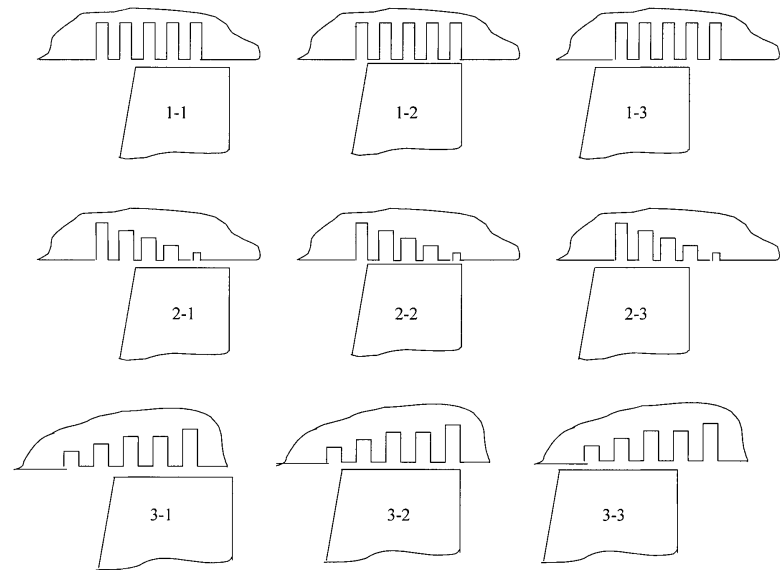

Fig. 4 Groove configurations of three types

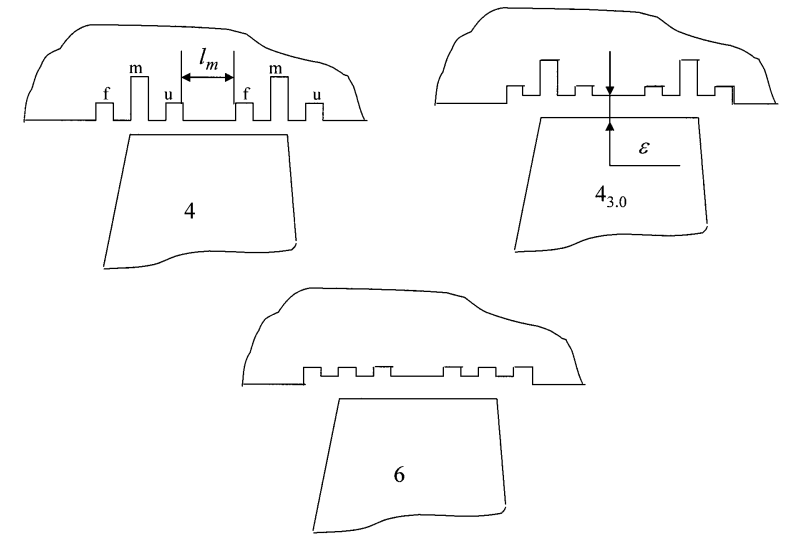

Fig. 5 Advanced groove configurations

Notes: 1 . The relative dimension $\left(\frac{h_{f, u}}{h_{m}}\right)_{4,6}$ is used only for the configurations 4 and 6 .

2. The relative tip clearance (nominal) for all tested configurations was equal $\bar{S}_{R}=1.3 \%\left(S_{R}=\right.$ $0.4 \mathrm{~mm}$ ).

3. The configurations $4_{3.0}$ and 6 have the relative effective tip clearance $\bar{\varepsilon}=3.0 \%(\varepsilon=0.9 \mathrm{~mm})$.

Main geometric parameters of tested grooves are presented in Tables 2 and 3. Tests of 1-, 2-, 3- and 6 groove configurations were carried out at the stage IX, configuration 4 - at the different compressor objects.

It was planned to research groove configurations with decreased (2-) and increased (3-) groove depth $h_{g}$ downstream the rotor blade tip. This parametric investigation includes traditional (with constant groove depth) configurations (1-) too. Besides, every distribution of the groove depth has different location of groove configuration relative to the rotor blade tips $\left(t_{1}=7 ; 2 ;-3 \mathrm{~mm} ; t_{2}=-7 ;-2\right.$; $3 \mathrm{~mm}$ ).

Results of this parametric investigation are presented in Table 2 and at Fig. 6. Main conclusions of the tests are the next:

1. For efficiency increase and stable operation range
Table 2 Main geometric parameters and results of testing of 12-3- groove configurations

\begin{tabular}{ccccccc}
\hline Index & $n_{g}$ & $\begin{array}{c}\mathrm{h}_{\mathrm{g}}, \mathrm{mm} \\
\text { (from the left to the right) }\end{array}$ & $\begin{array}{c}\mathrm{l}_{\mathrm{g}}=\mathrm{l}_{\mathrm{c}}, \\
\mathrm{mm}\end{array}$ & $\mathrm{t}_{\mathrm{l}}, \mathrm{mm}$ & $\Delta \eta, \%$ & $\Delta A, \%$ \\
\hline $1-1$ & 5 & 5 & 2 & 7 & -0.01 & -8.93 \\
$1-2$ & 5 & 5 & 2 & 2 & -1.01 & -5.82 \\
$1-3$ & 5 & 5 & 2 & -3 & 1.07 & -7.36 \\
$2-1$ & 5 & $5 ; 4.5 ; 4,3,2$ & 2 & 7 & -0.29 & -0.60 \\
$2-2$ & 5 & $5 ; 4.5 ; 4 ; 3 ; 2$ & 2 & 2 & 1.55 & -4.02 \\
$2-3$ & 5 & $5 ; 4.5 ; 4: 3: 2$ & 2 & -3 & 0.31 & -9.06 \\
$3-1$ & 5 & $2 ; 3 ; 4 ; 4.5 ; 5$ & 2 & 7 & 0.37 & -4.80 \\
$3-2$ & 5 & $2 ; 3 ; 4 ; 4.5 ; 5$ & 2 & 2 & -0.52 & -2.14 \\
$3-3$ & 5 & $2 ; 3 ; 4 ; 4.5 ; 5$ & 2 & -3 & 0.96 & 0.03 \\
\hline
\end{tabular}

Table 3 Main geometric parameters and results of testing of new groove configuration (4)

\begin{tabular}{|c|c|c|c|c|c|c|c|c|}
\hline Object In & ndex & $\mathrm{H}_{\text {(fr }}$ & $\begin{array}{l}\mathrm{h}_{\mathrm{g}}, \mathrm{mm} \\
\text { the left to the right) }\end{array}$ & $\begin{array}{l}\mathrm{l}_{\mathrm{g}}=\mathrm{I}_{\mathrm{c}}, \\
\mathrm{mm}\end{array}$ & $t_{1}, m m$ & $\varepsilon, \%$ & $\Delta \eta, \%$ & $\Delta A, \%$ \\
\hline Compressor & $\mathrm{V}+\mathrm{VI}$ & 6 & $2 ; 5 ; 2 ; \ldots ; 2 ; 5 ; 2$ & 2 & 4 & 2.6 & -2.70 & 1.00 \\
\hline \multirow[t]{5}{*}{ Rotor } & R-VIII & 6 & $2 ; 5 ; 2 ; \ldots ; 2 ; 5 ; 2$ & 2 & 4 & 1.3 & 0 & -3.00 \\
\hline & & & & & & 2.0 & -1.00 & -2.00 \\
\hline & & & & & & 3.0 & -3.80 & -1.50 \\
\hline & & & & & & 4.0 & -4.70 & 3.50 \\
\hline & & & & & & 5.0 & -6.10 & -2.20 \\
\hline \multirow[t]{2}{*}{ Stage } & IX & 6 & $2 ; 5 ; 2 ; \ldots ; 2 ; 5 ; 2$ & 2 & 4 & 1.3 & 0.80 & -5.40 \\
\hline & & & & & & 3.0 & -0.26 & 1.60 \\
\hline Compressor & VIII+IX & 6 & $2 ; 5 ; 2 ; \ldots ; 2 ; 5 ; 2$ & 2 & 4 & 1.3 & -3.43 & -0.90 \\
\hline Block & $\mathrm{V}+\mathrm{R}-\mathrm{VI}$ & 6 & $2 ; 5 ; 2 ; \ldots ; 2 ; 5 ; 2$ & 2 & 4 & 1.3 & -3.30 & -0.90 \\
\hline \multirow[t]{5}{*}{ Block } & VIII+R-IX & & $2 ; 5 ; 2 ; \ldots ; 2 ; 5 ; 2$ & 2 & 4 & 1.3 & -1.80 & -3.00 \\
\hline & & & & & & 2.0 & -4.00 & -2.00 \\
\hline & & & & & & 3.0 & -4.20 & -1.50 \\
\hline & & & & & & 4.0 & -5.80 & 3.50 \\
\hline & & & & & & 5.0 & -7.00 & 2.20 \\
\hline
\end{tabular}
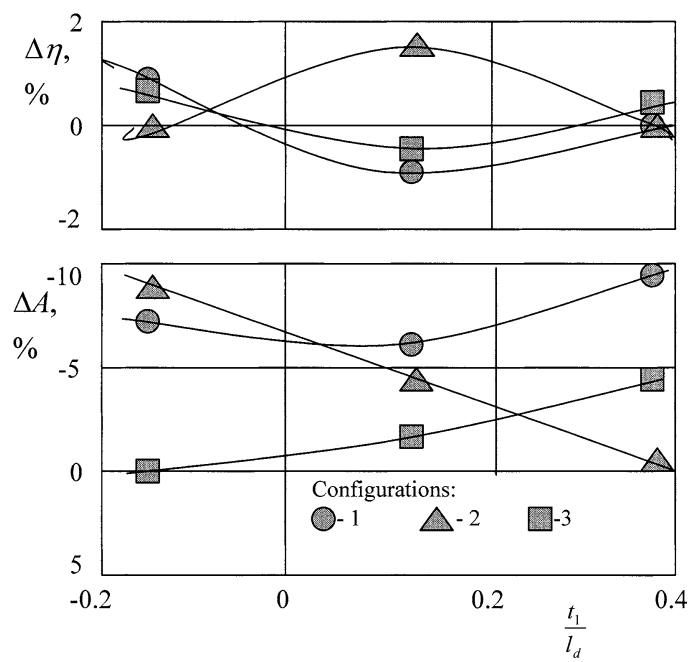

Fig. 6 Relationship between changes of main compressor parameters and inlet distance of groove 


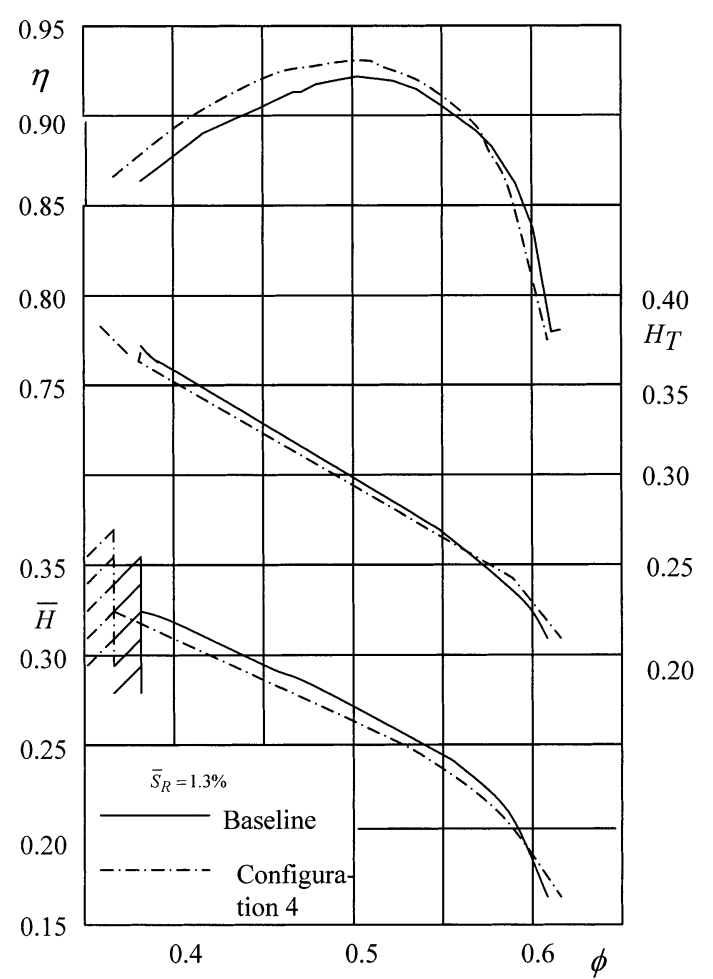

Fig. 7 Performance curves of the AI-24-IX stage with baseline and groove configuration 4

extension with the traditional groove configurations (1-) it is useful to increase $\pm t_{1}$, i.e. to shift the groove up or downstream.

2. With the new configurations (2-) it is useful to keep the value of $t_{1}$ near zero for efficiency improvement, but to increase $t_{1}$ (i.e. to shift groove downstream) for stable range extension.

3. With the new configurations (3-) it is useful to increase $\pm t_{1}$ (practically equally with the configurations 1 for efficiency improvement), but to decrease $t_{1}$ (i.e. to shift groove upstream) for stable range extension.

In any case these investigations have demonstrated that change groove depth along blade tip projection expands possibilities of casing treatment means. Note that the configuration 3- is rather similar with entire annular recess of sloped form ${ }^{(7),(8)}$.

The obtained results have permitted to continue development of new groove configurations. In particular, a principal idea was that grooves with different depth distribution may be located only at the entrance and exit of blade tip projection, in active zones of rotor flow. Such constructions $(4,6)$ may be featured by decreased loss and increased efficiency.

The configuration 4 was tested under various conditions (with the stage compressor IX, double-stage compressors $\mathrm{V}+\mathrm{VI}$, VIII+IX, blocks V+R-VI and VIII+R-IX, and rotor R-VIII, with relative effective tip clearances $\bar{\varepsilon}$ from 1.3 to $5.0 \%$ ). For the demonstration, performance

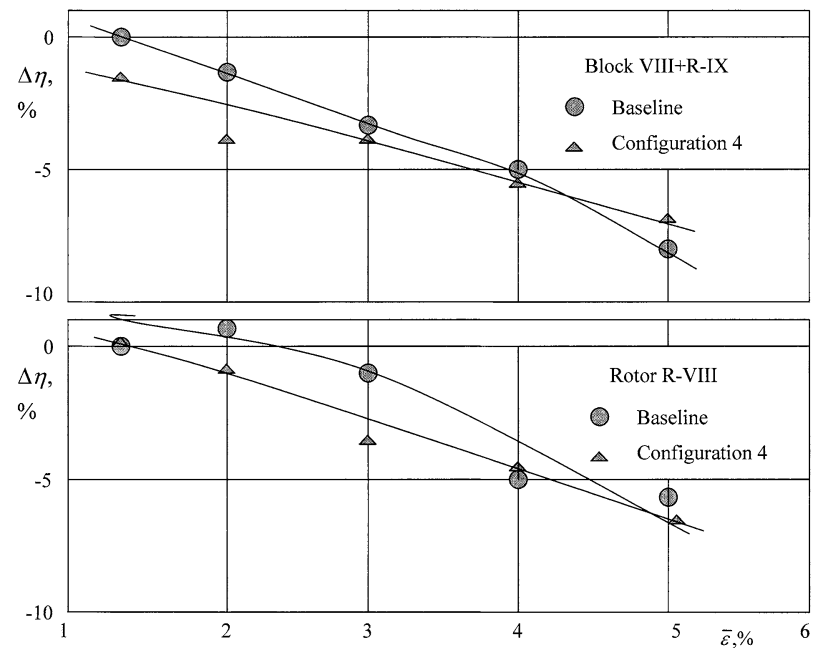

Fig. 8 Relationship of efficiency change versus relative effective tip clearance

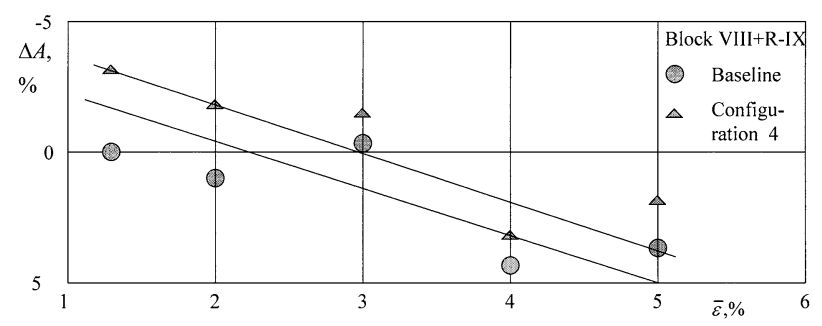

Fig. 9 Relationship of stable operation range change versus relative effective tip clearance

curves of the stage IX with baseline and groove configuration 4 are presented in Fig. 7.

Series of results have shown a negative influence on object efficiency (Table 3, Figs. 8 and 9). However, in the case of groove configuration 4 at the stage IX with relative tip clearances $\bar{S}=\bar{\varepsilon}=1.3 \%$ (absolute tip clearances $S=$ $\varepsilon=0.4 \mathrm{~mm}$ ) the efficiency increased by $0.8 \%$ with $5.4 \%$ stable range extension.

\section{Use of Group Method of Data Handling}

Data resulting from a large amount of testing have enabled compressor designers to utilize casing treatment for improving performance and/or stability of axial flow compressors. However, attempts to optimize groove configurations have been carried out nearly almost by empirical methods. In particular, there is at present no fundamental theoretical understanding of the mechanism by which the grooves alter the behavior (especially, efficiency) of the compressor. So development of the proper statistical models is sufficiently progressive way to date.

For development of effective statistical model accounting influence of several parameters on output function the Group Method of Data Handling (GMDH) was used $^{(9),(10)}$. This method is intended for data files with a limited number of experimental points. It permits combining an influence of all considered parameters in entire 
structural form. As this method is not very known and widely used, it is necessary to describe it in brief.

The GMDH is an original method of solving of problems of structural-parametric identification of models, or simulating on basis of experimental data under condition of uncertainty. Such problem consists in obtaining the mathematical model which approaches an unknown relationship of functioning of studied object (process). And information about this relationship is present in implicit form within a sample (file) of existing data. The GMDH differs from other methods by application of principles of automatic generation of variants - inconclusive solutions, and by successive selection with the help of external criteria for definition of models of optimal complexity.

The GMDH relates to the group of methods of "cross model validation" (as distinct from methods of applied regression analysis and methods "with explicit limitation of model complexity") for solution of simulation problems.

The GMDH procedure consists in optimization of model structure and parameters with the help of expedient enumeration of possibilities for automatically generated model variants within the set class of basic models and with the help of external criteria based on a sample fragmentation.

In the presence of the GMDH-algorithms, it is possible to simulate static objects, time series and dynamic objects (processes) within the next main classes of models: linear, polynomial, additive-multiplicative, harmonic, autoregressive, difference etc.

During enumeration of model possibilities it may be convenient to use generators of structures of enumerating and multiseries types, at that rate the last ones are completely original, and the first ones in particular case (under abandoned principle of inconclusive solutions, or freedom of choice) emulate the procedures of test of all regressions, branches and bounds, or step-by-step regression.

So, the GMDH is designed for models definition of technical, technological, ecological and others complex objects and processes using experimental data under condition of uncertainty, featured by limited numbers of noise observations, incomplete information about structure of significant variables and internal correlations of object (process).

\section{Development of Casing Treatment Statistical Model}

For the model development it was applied the program of structural identification of algebraic models with orthogonalization of particular descriptions and with the external criterion of regularity.

The groove geometric parameters in relative form were considered with respect to their influence on compressor efficiency $\left(\frac{l_{d}}{l_{p}}, \frac{\varepsilon}{h_{1}}, \frac{l_{m}}{l_{d}},\left(\frac{h_{f, u}}{h_{m}}\right)_{4,6}\right)$ and stable opera- tion range $\left(\frac{\varepsilon}{h_{1}}, \frac{h_{f}}{h_{m}}, \frac{h_{u}}{h_{m}}\right)$. The choice of these parameters was proved by preliminary use of GMDH-algorithms.

Note: $h_{1}$ is a blade height at the rotor inlet.

Relationships between every groove parameter and efficiency change are presented at Fig. 10(a) and (b). Application of GMDH-method has permitted to combine influences of several parameters to one relationship (Fig. 11). It is a dependence function of relationship between experimental and model (obtained with the help of GMDH-algorithm) efficiency change. This function accounts the influence of four arguments (parameters), selected by GMDH.

Formula of the relationship for efficiency change:

$$
\begin{aligned}
Y_{1} & =C_{0}+C_{1}\left(X_{2}\right)^{-1}+C_{2}\left(X_{5}\right)\left(X_{9}\right)+C_{3}\left(X_{5}\right)^{-1}\left(X_{8}\right) \\
& +C_{4}\left(X_{2}\right)\left(X_{9}\right)^{-1}+C_{5}\left(X_{8}\right),
\end{aligned}
$$

where

$$
\begin{aligned}
& Y_{1}=\Delta \eta_{\mathrm{mod}} ; X_{2}=\frac{l_{d}}{l_{p}} ; X_{5}=\frac{\varepsilon}{h_{1}} ; X_{8}=\frac{l_{m}}{l_{d}} ; X_{9}=\left(\frac{h_{f ; u}}{h_{m}}\right)_{4,6} \\
& C_{0} \ldots C_{5} \text { - constants. }
\end{aligned}
$$

For this specific database example $C_{0}=-13.568 ; C_{1}=$ 20.586; $C_{2}=-301.833 ; C_{3}=-0.0663 ; C_{4}=0.489 ; C_{5}=$ -1.941 .
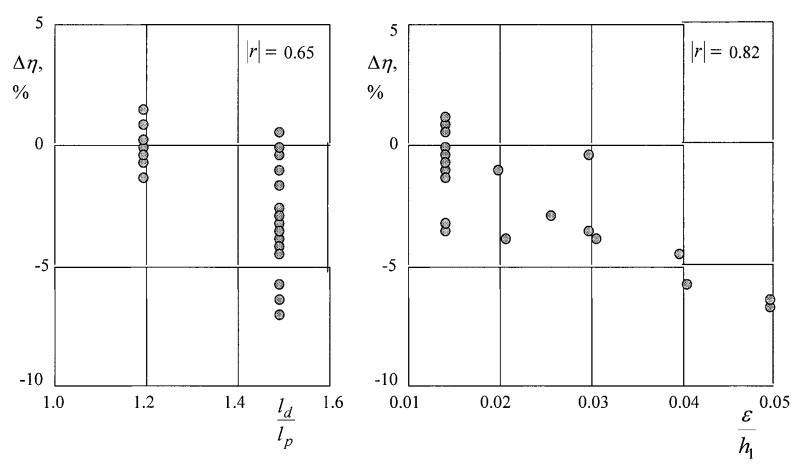

(a)
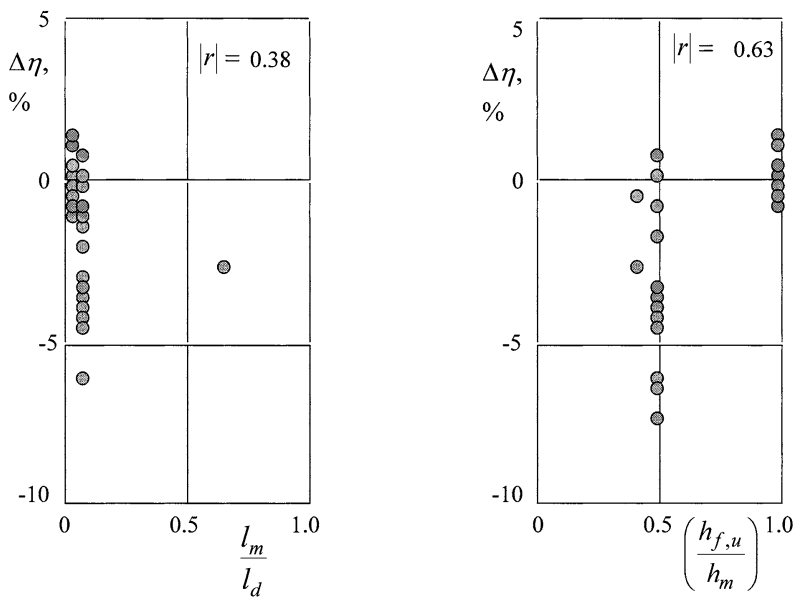

(b)

Fig. 10 Influence of geometric parameters on change of compressor efficiency (for configurations 1...4) 


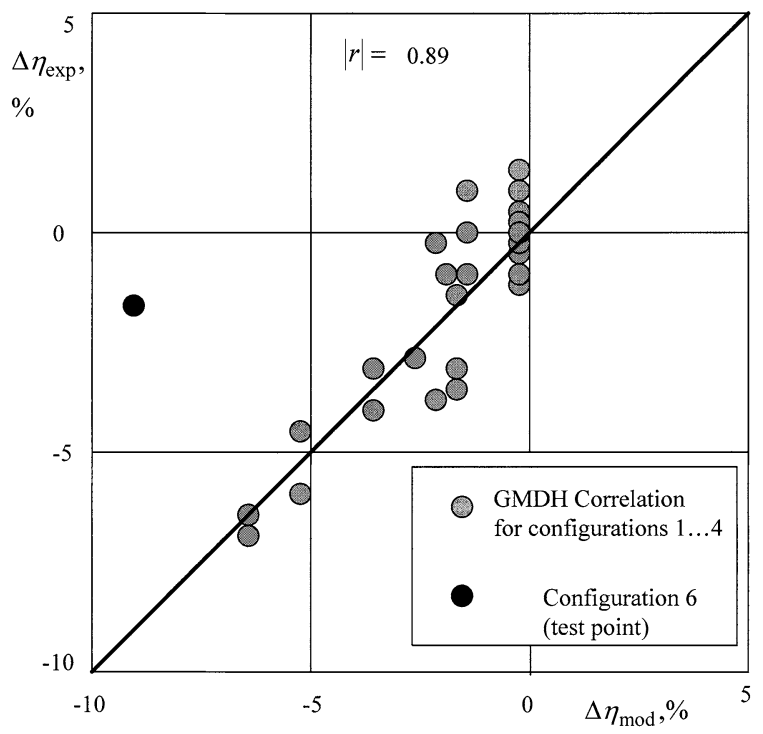

Fig. 11 Relationship between experimental and model changes of compressor efficiency

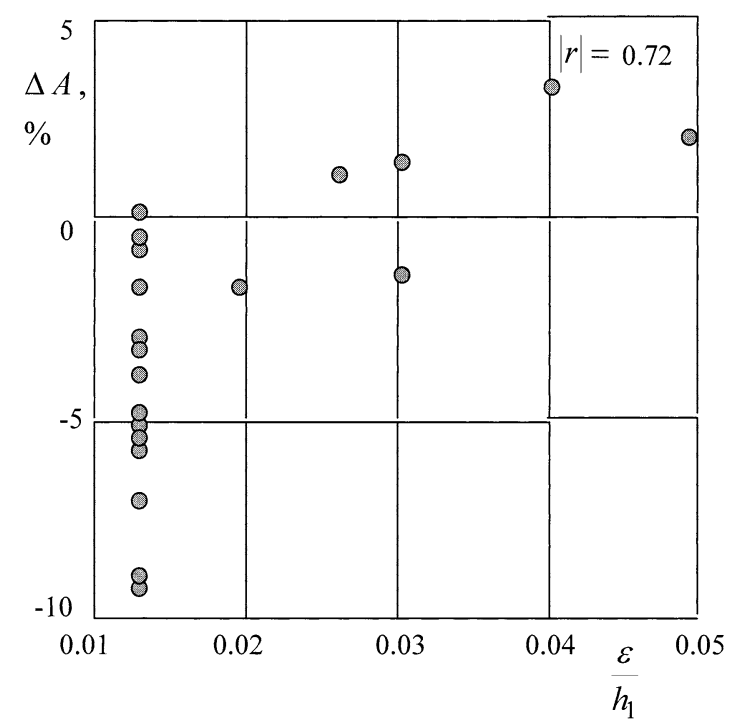

(a)
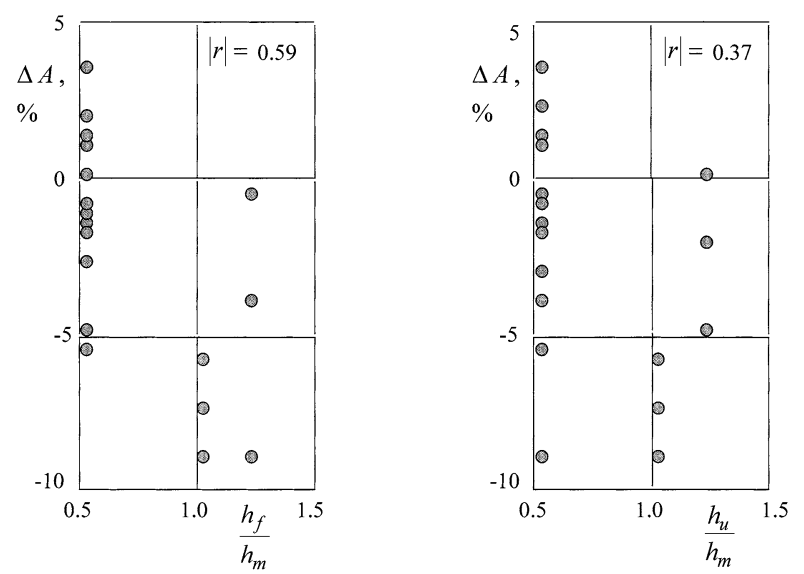

(b)

Fig. 12 Influence of geometric parameters on change of compressor stable operation range (for configurations $1 \ldots 4)$
Test point (small black circle) features an influence of the new groove configuration 6 with the parameters:

$$
\frac{l_{d}}{l_{p}}=1.53 ; \frac{\varepsilon}{h_{1}}=0.03 ; \frac{l_{m}}{l_{d}}=0.13 ;\left(\frac{h_{f, u}}{h_{m}}\right)_{4,6}=1.0 ;
$$

Evidently, the test point is located relatively far from the function line. It may be explained by forced selection of the configuration 6 for the test purpose in the absence of any configuration similar with the configuration 4 . So this relationship may be used at the first stage of groove designing.

Results for compressor stable operation range were processed in the same manner. Relationships between every groove relative parameter and stable range change are presented at Fig. 12 (a) and (b). Application of GMDHmethod has permitted obtaining the relationship presented at Fig. 13.

Formula of the relationship for the stable operation range:

$$
Y_{2}=C_{0}+C_{1}\left(X_{6}\right)^{-1}+C_{2}\left(X_{5}\right)\left(X_{6}\right)+C_{3}\left(X_{5}\right)\left(X_{6}\right)\left(X_{7}\right),
$$

where $Y_{2}=\Delta A ; X_{5}=\frac{\varepsilon}{h_{1}} ; X_{6}=\frac{h_{f}}{h_{m}} ; X_{7}=\frac{h_{u}}{h_{m}} ; C_{0} \ldots C_{3}$ constants.

For this specific database example $C_{0}=-14.730$; $C_{1}=5.351 ; C_{2}=329.353 ; C_{3}=-97.194$. The test point (groove configuration 6, small black circle) is located relatively close to the function line.

As it is may be observed, the model functions combine influences of several geometric parameters in entire common structural form. The presented relationships are rather close to linear polynomial ones.

Approximating relationship on "Efficiency change Stall margin improvement" (Fig. 14) proves the global

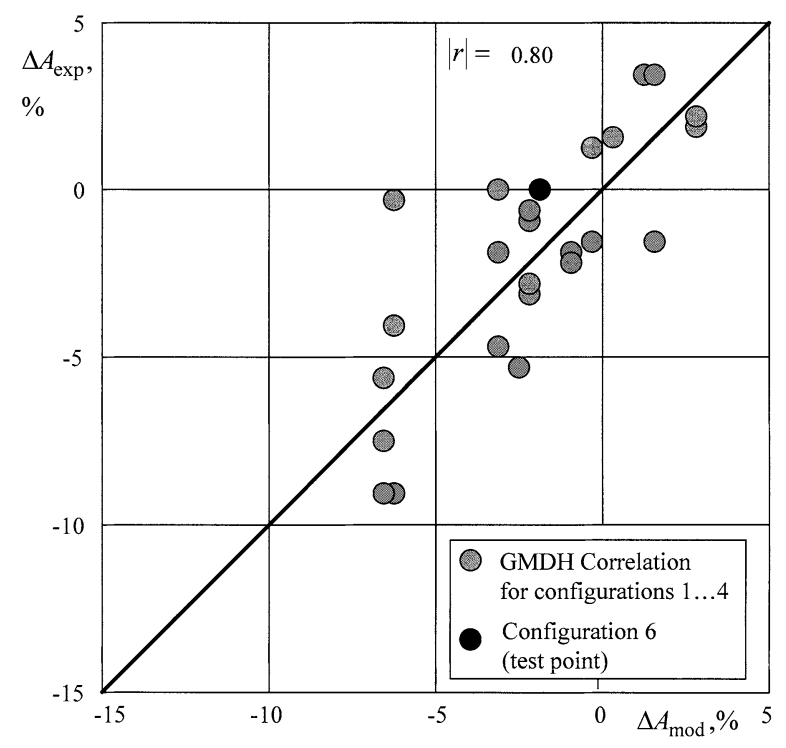

Fig. 13 Relationship between experimental and model changes of compressor stable operation range 


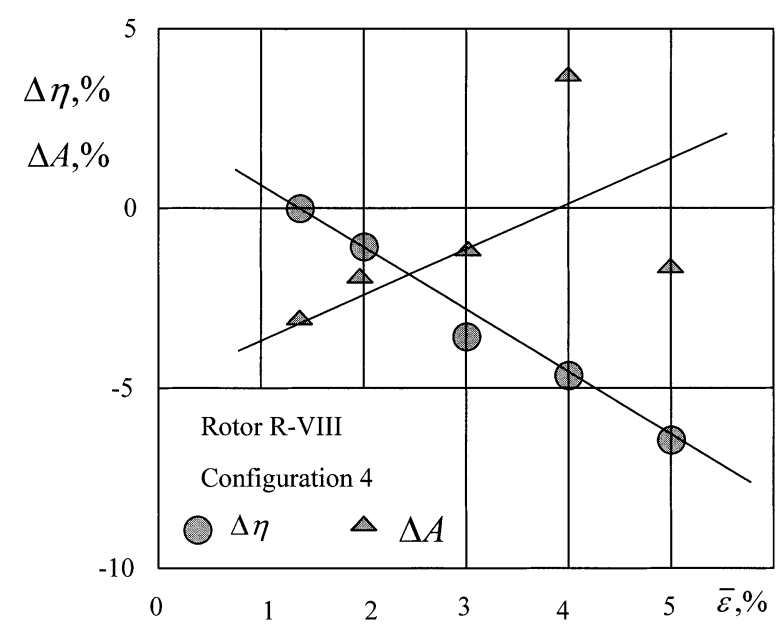

Fig. 14 Approximating relationship on "Efficiency change Stall margin improvement"

conclusion about contrary influence of casing treatment upon efficiency and stable operation range.

And then, special calculations with the help of the developed model formulae have permitted estimating of degree of every parameter influence upon final function. It was concluded that the most effect has $\frac{l_{d}}{l_{p}}$ for the compressor efficiency change, and $\frac{h_{f}}{h_{m}}$ for the compressor stable operation range change. Such results may be useful for a practical casing treatment design.

\section{Discussion}

The study of casing treatment in the axial flow compressor has been carried out for more than 30 years, and has obtained remarkable achievements. There have been a number of papers about the mechanism of casing treatment (e.g., Refs. (2), (5) and (11)-(13), etc.). But up now the mechanism of casing treatment influence remains poorly understood.

At one view, the behavior of casing treatment seems rather simple. There exists a pressure difference between the pressure and suction sides of blade. It leads to the occurrence of the tip leakage flow and its resulting vortex, deteriorating the compressor performance.

Casing treatment is able to effectively extend the stall margin by weakening or even destroying the tip leakage vortex $^{(14),(15)}$. The stall margin improvement is largely due to removal of flow from the blade tip to the recess, and the elimination of the growth of the stall region at the tip, which occurs at stall in the solid casing build. The measurements indicate a strong radial flow from the rotor tip into the treatment recess. When the treatment is applied, this tip flow passes radially into the treatment recess, and then discharges out into the main flow ${ }^{(16)}$.

And the more the recess volume, with stall margin improvement, the more efficiency penalty because of ad- ditional losses. Smooth recess outlet permits decreasing these losses. The sloped (triangular) recess has the best efficiency performance, due to its elimination of the forward-faced step inherent in the cylindrical (rectangular) recess ${ }^{(7),(17)}$.

The axial position of the treatment relative to the rotor chord is very important. In the paper ${ }^{(18)}$ the 3-D flow field in the tip region was studied, and it was found that the tip leakage flow originates near the quarter chord and peaks around the mid chord. It was also concluded from the simulation $^{(18)}$ that it was more advantageous to manipulate the tip leakage flow only in the very upstream part of the blade chord, than over the complete width.

The present paper proves that different distribution of groove depth along the chord may be useful variable for effective design. Smooth inlet and outlet of casing treatment device permits conserving or even some efficiency increasing under stall margin improvement.

\section{Conclusions}

1. Casing treatment in the form of circumferential grooves in compressor casing over rotor blade tips may be effective means for extension of compressor stable operation range. Influence upon compressor efficiency is negative as a rule.

2. Special parametric investigation has demonstrated an importance of change of groove depth distribution along rotor blade for developing new groove configurations. In some cases such new devices may increase compressor efficiency.

3. The statistical model on the base of experimental data processing with the help of Group Method of Data Handling permits previous evaluation of results of groove casing treatment application (efficiency change for configurations $1 \ldots 4$, stable operation change for configurations $1 \ldots 4,6)$.

4. The most effective are parameters $\frac{l_{d}}{l_{p}}$ for the compressor efficiency change and $\frac{h_{f}}{h_{m}}$ for the compressor stable operation range change.

5. Perfection of new developed configurations and models requires new tests and investigations.

\section{References}

( 1 ) Fabri, J. and Rebeux, J., Effect of Outer Casing Treatment on Stall Margin of a Supersonic Rotating Cascade, Proc. Gas Turbine Conf., ASME, (1975).

( 2 ) Takata, H. and Tsukuda, Y., Stall Margin Improvement by Casing Treatment - Its Mechanism and Effectiveness, Trans. ASME, J. Eng. for Power, Vol.99 (1977), pp.121-133.

( 3 ) Greitzer, E.M., Review - Axial Compressor Stall Phenomena, Trans. ASME, J. Fluid Eng., Vol.102 (1980), pp.134-151.

(4) Rabe, D.C. and Hah, C., Application of Casing Cir- 
cumferential Grooves for Improved Stall Margin in a Transonic Axial Compressor, ASME Paper GT-200230641, (2002).

( 5 ) Greitzer, E.M., Nikkanen, J.P., Haddad, D.E., Mazzawy, R.S. and Joslin, H.D., A Fundamental Criterion for the Application of Rotor Casing Treatment, Trans. ASME, J. Fluid Eng., Vol.101 (1979), pp.237243.

( 6 ) Osborn, W., Lewis, G. and Heidelberg, L., Effect of Several Porous Casing Treatment on Stall Limit and on Overall Performance of an Axial - Flow Compressor Rotor, NASA Lewis RC, TN D-6537, (1971).

( 7 ) Wisler, D.C. and Beacher, B.F., Improved Compressor Performance Using Recessed Clearance (Trenches), J. Propulsion, Vol.5 (1989), pp.469-475.

( 8 ) Yershov, V.N., Efimenko, A.P. and Nezym, V.Yu., Study of Flow Control Device in the Form of an Annular Recess in the Compressor Case, Izvestiya Vysshikh Uchebnykh Zavedenij. Aviatsionnaya Tekhnika, Vol.1 (1984), pp.85-86.

(9) Ivakhnenko, A.G., Articles, Papers, Books and Software on the Group Method of Data Handling (GMDH), web-site: www.gmdh.net/articles

(10) Ivakhnenko, A.G. and Yurachkovsky, Yu.P., Complicated Systems Modelling Using Empiric Data, Radio and Communications, Moscow, (1987), p.120.

(11) Smith, G.D.J. and Cumpsty, N.A., Flow Phenomena in Compressor Casing Treatment, Trans. ASME, J. Eng. Gas Turbines and Power, Vol.106 (1984), pp.532-541.
(12) Johnson, M.C. and Greitzer, E.M., Effects of Slotted Hub and Casing Treatments on Compressor Endwall Flow Fields, ASME Paper 86-GT-247, (1986).

(13) Crook, A.J., Greitzer, E.M., Tan, C.S. and Adamczyk, J.J., Numerical Simulation of Compressor Endwall and Casing Treatment Flow Phenomena, Trans. ASME, J. Turbomachinery, Vol.115 (1993), pp.501-512.

(14) Wilke, I. and Kau, H.-P., A Numerical Investigation of the Flow Mechanisms in a HPC Front Stage with Axial Slots, Proc. ASME TURBO EXPO 2003, Atlanta, Georgia, USA, GT2003-38481, (2003).

(15) Yang, H., Nuernberger, D., Nicke, E. and Weber, A., Numerical Investigation of Casing Treatment Mechanisms with a Conservative Mixed-Cell Approach, Proc. ASME TURBO EXPO 2003, Atlanta, Georgia, USA, GT2003-38483, (2003).

(16) Kang, C.S., McKenzie, A.B. and Elder, R.L., Recessed Casing Treatment Effects on Fan Performance and Flow Field, ASME TURBO EXPO 1995, Paper 95-GT-197, (1995).

(17) Nezym, V.Yu., Casing Treatment of Various Types in Compressor Stage: Parametric Representation, Proc. Int. Pipeline Conf. (ASME), Calgary, Canada, ASME Paper IPC02-27066, (2002).

(18) Lakshminarayana, B., Pougare, M. and Davino, R., Three-Dimensional Flow Field in the Tip Region of a Compressor Rotor Passage, Trans. ASME, J. Eng. for Power, Vol.104 (1982). 